\title{
A INFLUÊNCIA DOS TIPOS DE MARCA SOBRE A ESCOLHA E A PRECIFICAÇÃO DE UMA CAMISETA
}

\author{
Data de submissão: 16/09/2014 \\ Aceite: $26 / 07 / 2016$ \\ Maria Aparecida Gouvêa ${ }^{1}$ \\ Luiz Alberto Marcondes Homen de Mello Castro ${ }^{2}$ \\ Noel Alves Vicente ${ }^{3}$
}

\section{RESUMO}

As marcas de roupas comunicam a identidade social e associam a pessoa que a consome a um grupo. Cientes disso, diversas marcas foram criadas, algumas exploram a relação com o mundo da moda e outras buscam associação a uma causa. A fim de ampliar o conhecimento sobre a influência das marcas, este estudo se propôs a analisar o impacto dos tipos de marcas (social, genérica e de fabricante), sobre a escolha e o preço de uma camiseta. Realizou-se pesquisa quantitativa com uma amostra acidental de 248 pessoas com alto grau de instrução. Por meio da análise conjunta, obteve-se um modelo que hierarquizou três atributos pela importância na escolha de uma camiseta e em cada atributo os aspectos mais relevantes. Avaliou-se, também, a relação dos três tipos de marca com o preço de uma camiseta. $O$ trabalho revelou que a qualidade, neste segmento, é mais importante que a marca, e que diferentes tipos de marcas podem agregar valor a um produto em níveis variados dependendo do segmento de consumidores.

Palavras-chave: Marca de Fabricante. Marca Social. Marca Genérica. Camisetas.

1 Possui graduação em Bacharelado em Estatística pela Universidade de São Paulo, USP, graduação em Bacharelado em Letras pela USP, mestrado em Estatística pela USP e doutorado em Administração pela USP. São Paulo - SP. Brasil E-mail: magouvea@usp.br

2 Possui graduação em Administração de Empresas pela Universidade de São Paulo, USP e mestrado em Administração de Empresas pela USP. E-mail: castro.beto@gmail.com.

3 Possui graduação em Estatística pelo Centro Universitário Capital, UNICAPITAL e mestrado em Métodos Quantitativos/Informática pela Faculdade de Economia, Administração e Contabilidade - USP, FEAC/USP E-mail: noelvicente@usp.br. 


\section{INTRODUÇÃO}

Com a proliferação dos produtos presentes nos mercados e com a base econômica dos países deslocando-se do sistema produtivo para o consumo, houve um movimento da racionalidade material para o plano do desejo e, portanto, para o campo da subjetividade (ELLWOOD, 2004). Agora, é o imaterial que move o consumo; assim, o conceito e a marca que anima o produto são mais responsáveis pela sua escolha do que a sua qualidade (KAPFERER, 2004b).

Dois fatores que contribuíram para esse movimento são citados por Ellwood (2004). Um deles é a fragmentação das identidades pessoal e social do ser humano, o que encoraja a criação de uma identidade pessoal pelo consumo das marcas, ou seja, o homem é o que compra; assim, os consumidores passam a buscar em grande parte um conteúdo imaginário, intangível e simbólico nos produtos que consomem.

O outro fator é a globalização, que, conforme Kapferer (2004b, p. 69), "leva à difusão dos modelos e símbolos (portanto, marcas) através das fronteiras e das culturas, por meio da livre circulação de imagens" e, desse modo, complementa Ellwood (2004), faz o consumidor se perceber apenas como uma pequena parte de um todo e necessitar dos valores expressos pelas marcas consumidas para se orientar nesse mundo conectado.

Neste contexto, as marcas assumiram um papel de destaque nas relações de compra e venda, deixando a simples função de facilitadora das transações comerciais para tornarem-se poderosos signos de representação do ser, do comportamento, do posicionamento social e econômico (PEREZ, 2004; MORT et al., 2007; CALDWELL; COSHALL, 2002).

"O consumidor passou a valorizar cada vez mais as marcas, vistas como um indicador de garantia e qualidade e cuja imagem começou a ser aproveitada na elaboração de estratégias segmentadas" (GRANATO; PEREIRA, 2011, p. 14).

Com um papel ampliado, as marcas, de acordo com Mowen e Minor (2003), passaram a funcionar como um facilitador na tomada de decisão de compra de produtos complexos (ou seja, com características de difícil avaliação), e, também, tornaram-se, segundo Keller (2002), influenciadoras da qualidade percebida, preço justo e fidelidade; em outras palavras, transformaram-se em um item com muita força para alterar o valor percebido de um produto.

Essa mudança fica evidente no segmento de vestuário, pois, por ser um produto de consumo aparente, as marcas de roupas funcionam como um instrumento de comunicação da identidade social e de associação da pessoa que a consome a um grupo (CARROLL, 2009).

Belk (1988) apud Altaf et al. (2013) enfatiza que os produtos são excelentes fontes de informação sobre as pessoas que os consomem.

Assim, consumidores possuem uma melhor percepção de produtos que carregam uma marca conhecida, sendo o preço impactado por ela, embora o mesmo não ocorra com a qualidade (D’ASTOUS; SAINT-LOUIS, 2005).

Segundo Keller (1993) apud Velter et al. (2009), atributos são características que descrevem propriamente um produto, o qual um consumidor avalia ao realizar uma compra.

Na tomada de decisão de compra, o atributo de um produto é o principal estímulo que influencia o consumidor, avaliando-o em função de seus próprios valores, crenças ou experiências passadas (PETER e OLSON, 1996 apud VELTER et al., 2009).

De acordo com Szybilo e Jacoby (1974) apud Velter et al. (2009), para que um ato de compra se concretize, os consumidores, em geral, realizam uma avaliação e julgamento comparativo entre produtos e marcas. Esse processo de avaliação passa pelo julgamento de pistas associadas aos produtos. As pistas seriam entendidas então como os vários itens de informações 
sugestivas sobre o produto, as quais são identificadas, avaliadas e interpretadas para compor uma avaliação.

Informações disponíveis relativas aos produtos devem gerar respostas (atitudes e comportamento) dos consumidores.

Nesse contexto, considerando-se os atributos tipos de marca, preço e qualidade, no segmento de roupas, emerge a seguinte situação-problema: qual a influência dos tipos de marca, sobre a escolha e a precificação de uma camiseta?

O objetivo deste trabalho é estudar a influência de tipos de marcas (sociais, genéricas e de fabricante) sobre a escolha e a precificação de uma camiseta.

Para alcançar esse objetivo, procede-se com o estudo da:

Importância da marca na escolha de uma camiseta;

Predileção das pessoas diante de camisetas de marca social, genérica e de fabricante;

Relação dos três tipos de marca com o preço atribuído à camiseta.

Justifica-se este trabalho considerando-se a abrangência da difusão das marcas acarretando a importância da sua correta gestão, especialmente no segmento de roupas, como observado por (D'ASTOUS; SAINT-LOUIS, 2005), de modo que as empresas consigam sobreviver em um ambiente em que cada dia novas marcas aparecem e produtos de marcas genéricas vêm para conquistar espaço por meio de preços baixos, tornando-se fundamental a investigação da preferência do consumidor neste cenário.

Além disso, a decisão pelo uso de camisetas apoiou-se no fato de que este produto é um item comum para ambos os sexos e é acessível para quase todas as classes sociais, cuja marca, segundo Ellwood (2004), tem enorme valor, por ser um veículo de comunicação dos valores e da personalidade do usuário.

\section{FUNDAMENTAÇÃO TEÓRICA}

Esta seção é estruturada em quatro partes. A primeira foca no conceito e tipos de marca. Na sequência, têm-se a relação da marca com o preço, em seguida, com a qualidade percebida e finaliza-se com o consumo simbólico de marcas de camiseta.

\section{Tipos de marca}

No século XX, ampliando o seu papel nas empresas, a marca deixa a finalidade burocrática para assumir a responsabilidade de diferenciar os produtos e reduzir a importância do preço na decisão de compra, ao influenciar na percepção de valor dos produtos, assumindo, deste modo, a ideia de que é um ativo que possui um potencial para gerar valor para os seus acionistas. A marca passa a ser um signo capaz de adquirir significados múltiplos junto ao consumidor, passando para ele a posse da imagem da marca, que antes era do produtor (ELLWOOD, 2004).

Durante o movimento evolucionário da marca, alguns tipos de marca foram criados e, atualmente, eles coexistem no mercado. Dada a grande variedade, para viabilizar o estudo dos tipos de marca, realizou-se a categorização deles em três grandes conjuntos de marcas: marcas genéricas, marcas de fabricantes e marcas sociais.

As marcas genéricas possuem uma baixa identidade, privada de valores imateriais e com pouca ou nenhuma diferenciação (acarretando menores custos de embalagem, de divulgação e de 
monitoramento), e se posicionam no mercado como produtos de baixo preço e de qualidade igual ou um pouco inferior (mas, justa em relação ao preço pago) a de outras marcas fortes (KAPFERER, 2004a, 2004b). Conforme Kotler e Keller (2006), se a marca não possui diferencial em relação aos concorrentes, ela pode ser classificada como uma commodity ou uma versão genérica do produto.

As marcas de fabricante são, basicamente, as marcas top of mind ou referenciais, caracterizadas por possuírem um patrimônio construído sobre o seu know-how tecnológico e das necessidades do mercado; são marcas com tradição e reconhecimento entre os especialistas do produto ou serviço em questão e entre os consumidores. Normalmente, elas possuem celebridades ou especialistas endossando-as para confirmar as afirmações de autoridade ou desempenho e, desse modo, propõem uma relação de confiança com o consumidor; ao transmitir a ideia de que elas fazem a boa escolha por ele, por isso elas são a sua boa escolha (ELLWOOD, 2004; KAPFERER, 2004a).

Além disso, essas marcas têm forte identidade e, consequentemente, alta diferenciação; têm como característica o investimento de grandes quantias de dinheiro em comunicação e o uso de equipes dedicadas para a gestão da marca, a fim de garantir o alto valor delas e assegurar todos os benefícios que elas podem trazer. Essa forte identidade da marca tende a aumentar a intensidade do vínculo com o consumidor, dando-lhe profundidade emocional e tornando-a menos substituível (KAPFERER, 2004a).

A relação da marca de fabricante com o consumidor pode ser caracterizada como um contrato implícito especial, porque, de acordo com Kapferer (2004a, p. 44),

a marca forte possui, além de um produto e um serviço eficientes, um verdadeiro imaginário de marca, uma simbologia, seu consumo é tanto do produto como do símbolo. Consumimos a sua identidade em todas as suas facetas: 1 ) o físico da marca, seu produto, seu desempenho, seus serviços associados; 2 ) sua personalidade, levada ou não por um ícone de marca que estimula seu potencial simbólico; 3) seus valores [...]; 4) a relação proposta.

Segundo Ellwood (2004, p. 260), marcas de fabricantes "são uma vasta gama de marcas que satisfazem as necessidades psicológicas e sociológicas dos clientes por uma identidade pessoal ou status e por uma identidade de grupo ou filiação".

O grupo das marcas sociais ou marcas éticas é uma vertente das marcas de fabricante; assim, compartilha das mesmas características do grupo anterior, exceto pelo fato de que, ao invés de posicionarem-se como altamente tecnológicas e de prestígio, têm seu patrimônio baseado no conceito da responsabilidade social e financeira, da produção sustentável, com alto envolvimento com a natureza e a sociedade.

De acordo com Leitch e Davenport (2007), as causas socioambientais podem servir de veículo para a expressão da identidade pessoal e unir os seus adeptos em comunidades que se diferenciam umas das outras. Contudo, a fidelidade do consumidor pode ser à marca social ao invés de a uma organização particular, visto que múltiplas organizações podem estar associadas para desenvolver essa marca (LEITCH; DAVENPORT, 2007).

A marca social pode ser definida como um processo de formular e implementar um conceito de marca que é caracterizada pela contribuição a um determinado esforço que gera lucro social (benefícios sociais, ambientais e/ou humanitários); o qual, por sua vez, leva os consumidores a engajarem-se em uma transação geradora de receita para a empresa (GILLIGAN; GOLDEN, 2009).

As marcas sociais normalmente baseiam os seus apelos em uma ou mais das seguin- 
tes áreas: meio ambiente, comunidade, bem estar, diversidade, direitos humanos, desempenho financeiro responsável e justo e governança corporativa (BLOMQVIST; POSNER, 2004; BRONN; VRIONI, 2001; POLONSKY; JEVONS, 2006).

Estas marcas se apoiam nas mesmas crenças das marcas de fabricante; contudo, as empresas que as adotam têm pelo menos um objetivo não econômico relacionado ao bem-estar social e, para atingi-lo, usam seus recursos e/ou de um de seus parceiros, pois confiam que o consumidor está disposto a pagar mais por marcas que respeitam o sistema socioambiental. Segundo Ellwood (2004), usar as questões ideológicas contemporâneas, tais quais as sociais e ambientais, como uma essência da personalidade de uma marca, pode atrair um grupo crescente de consumidores que tenham convicções semelhantes.

As marcas sociais afetam a percepção dos consumidores e influenciam as suas atitudes em direção aos produtos que as usam, assim como melhoram a avaliação feita por eles dos produtos e das companhias que possuem essas marcas (HOEFFLER; KELLER, 2002; LAFFERTY et al., 2004; PRACEJUS et al., 2004). Porém, para ser bem sucedida, a marca social precisa superar o ceticismo inicial dos consumidores, transmitindo uma real motivação altruísta.

\section{A relação da marca com o preço}

A oferta e a comunicação das empresas foram construídas em torno de marcas que herdam, com o tempo, valores imateriais, significados e representações que as diferenciam e levam os clientes a apresentarem uma relação de dependência por elas e, desse modo, uma fraca sensibilidade ao preço, que os faz pagarem mais caro em comparação aos concorrentes diretos e ao preço justo da oferta, o que ultrapassa a simples realização das funcionalidades do produto (CRAVENS; PIERCY, 2007; KAPFERER, 2004a; LAMBIN, 2000).

A marca é um valor agregado do invisível, impalpável, daquilo que se esconde sob os benefícios materiais. Normalmente, é por esse valor agregado que o comprador está disposto a pagar, razão pela qual, aliás, às vezes se avalia o valor financeiro de uma marca, medindo-se a diferença de preço que o consumidor está disposto a pagar para adquirir o produto dessa marca em comparação a um idêntico, mas sem marca, ou de uma marca desconhecida (KAPFERER, 2004a).

Uma marca forte gera maiores retornos em lucratividade para a empresa devido à possibilidade de se cobrar um preço diferenciado, o qual é, normalmente, 20 a $25 \%$ maior do que o preço justo (FURRIER, 2008b; KOTLER; KELLER, 2006; SERRALVO; FURRIER, 2005). O preço diferenciado é o benefício econômico mais explícito de uma marca e tem correlação significativa com o desempenho financeiro nas perspectivas de longo prazo da empresa (FURRIER, 2008b). Ele representa a possibilidade de a empresa receber uma maior margem líquida por um produto. Reforçando este ponto, Aaker (1996, p. 321) afirma que

preço [...] [diferenciado] pode ser a melhor medida individual disponível do patrimônio da marca, porque ele captura diretamente a lealdade dos consumidores de um modo relevante. Se eles são leais, eles devem logicamente estar desejando pagar um preço [...] [diferenciado]; se eles não desejam pagar mais, o nível de lealdade é baixo.

Nenhuma fidelidade à marca é incondicional, e o preço é um indicador dos potenciais benefícios de uma marca (ELLWOOD, 2004; FURRIER, 2008b). Assim, é essencial ter uma política de preço adequada ao que a marca oferece. Ao mesmo tempo em que uma posição consolidada de marca permite a prática de preços diferenciados, um preço elevado demais em relação à qualidade e aos benefícios percebidos pelo consumidor gera a sua frustração (FURRIER, 2008b). Já um 
preço subestimado resulta na desvalorização da marca em comparação às semelhantes, o que é difícil de ser contornado posteriormente, pois se cria um ciclo descendente em que a redução do lucro leva ao menor investimento em comunicação e qualidade do produto o que reduz ainda mais as vendas e, consequentemente, o lucro (ELLWOOD, 2004).

\section{A relação da marca com a qualidade percebida}

De acordo com D’Emidio (2009, p. 19-20), “a qualidade percebida é o conhecimento que o consumidor tem da qualidade geral ou superioridade de um produto ou serviço pretendido, em comparação a alternativas".

Nem sempre a qualidade que uma empresa entrega é a mesma que o consumidor avalia ter recebido. Se uma empresa entrega uma qualidade maior do que a percebida, significa que ela está investindo mal os seus recursos, desperdiçando-os. Entretanto, quando a qualidade entregue é menor que a percebida, isto leva a crer que a empresa utilizou tão bem seus recursos que geraram um resultado alavancado, ou seja, maior do que seria em condições normais.

A qualidade percebida é ampliada pelas marcas fortes, pois a pessoa passa a entender que não são somente os itens tangíveis (como desempenho, durabilidade, forma e acabamento do produto) que a marca está entregando, mas também aspectos emocionais, intangíveis, que aumentam a qualidade, embora não possam ser avaliados fisicamente. Outro motivo para essa percepção alavancada é o fato de que o consumidor interpreta o alto investimento de marketing na marca e o alto preço dela como indicativos de qualidade do produto (AAKER, 1996).

Este relacionamento entre marca forte e alta qualidade é feito muito comumente na compra de produtos e serviços complexos (como cremes anti-idade, cirurgias médicas, cortes de cabelo) que possuem itens de difícil avaliação. Como os consumidores raramente têm todas as informações necessárias para fazer um julgamento racional e objetivo sobre a qualidade - e mesmo que eles tenham as informações, eles podem não ter tempo e motivação para processá-las - eles confiam em uma ou duas pistas que associam com a qualidade (MOWEN; MINOR, 2003).

As marcas podem ser um desses sinais de qualidade e, dessa maneira, consumidores satisfeitos podem facilmente optar novamente pelo produto (KOTLER; KELLER, 2006).

Destacando a importância deste benefício gerado pela marca, Aaker (1996, pp. 17-19) afirma que a "qualidade percebida está normalmente no coração do que os clientes estão comprando e, neste sentido, ela é uma medida básica do impacto de uma identidade de marca".

\section{O consumo simbólico de marcas de camisetas}

Com o fortalecimento do aspecto simbólico das marcas, os indivíduos têm visto as marcas como reflexo e parte deles mesmos, capazes de gerar aceitação social. Assim, buscam consumir produtos que não expressam necessariamente o que a pessoa realmente é, mas como ela gostaria de ser na realidade ou de ser vista, a fim de aumentar o pertencimento social por meio da associação a um grupo e a marcar a sua posição na sociedade (CARROLL, 2009).

O impacto da imagem da marca pode, contudo, ser moderado pelo tipo de produto e pode ser menos aparente em categorias de produtos que não são vistas como veículos de autopromoção (CARROLL, 2009). Diversos estudos têm demonstrado o uso das roupas como um código, uma linguagem que permite uma mensagem ser criada e (seletivamente) entendida. Assim, elas acabam sendo um meio de comunicação da identidade social, status e dos valores expostos por um grupo (CARROL, 2009; PHAU; LENG, 2008). Desse modo, em camisetas, a marca e os seus 
significados têm enorme valor, conforme observa Ellwood (2004, pp. 204-205) ao relatar que

a aprovação sociológica da marca deriva da satisfação que os clientes obtêm da associação e do reconhecimento do grupo [...]. As roupas de marca são claramente usadas para permitir a inclusão em um grupo social especifico, ou podem excluir as pessoas de um grupo. O que as roupas dizem sobre quem as usa foi traduzido em grande parte no lema "você é o que você usa"; seus companheiros de grupo o reconhecem como alguém da mesma categoria e interagem com você com base em que vocês têm alguma coisa em comum. O fato de usar roupas de uma determinada marca representa uma afirmação de valores que pode ser interpretada pelos outros. [...] Esse tipo de aprovação da marca baseia-se no reconhecimento e na compreensão de uma identidade de grupo, para satisfazer as necessidades de socialização. É duvidoso sugerir que um simples distintivo pode definir o nosso caráter, mas as pesquisas sugerem que a maioria das pessoas confia em parte nesse tipo de simbolismo. [...] Os consumidores podem comunicar identidades verdadeiras ou desejadas para o seu grupo.

\section{ASPECTOS METODOLÓGICOS}

Realizou-se uma pesquisa exploratória quantitativa com o uso de dados primários. A população de interesse correspondia aos brasileiros maiores de 18 anos de ambos os sexos. A escolha de pessoas com 18 anos ou mais foi devido ao fato de que é um grupo que já faz parte da população economicamente ativa e, portanto, possui poder de compra para adquirir bens e serviços. Segundo Furrier (2008a), há indícios de que pessoas com baixo nível de escolaridade possuem menor grau de consciência de marcas devido à menor instrução. Diante disso, decidiu-se focar somente em pessoas com graus mais altos de escolaridade.

Foi empregada a amostragem acidental, e a coleta de dados foi realizada por meio de uma abordagem pela internet. O plano para a obtenção das respostas consistiu em disponibilizar o questionário em um site especializado, denominado QuestionPro, e divulgá-lo pelo envio do seu endereço, via correio eletrônico, para pessoas conhecidas responderem e para secretarias de alguns cursos de pós-graduação repassarem para os seus alunos, a fim de que eles participassem. Escolheram-se por conveniência as instituições contatadas, as quais se distribuem ao longo de todas as regiões do território brasileiro. Esse levantamento de dados ocorreu em março e em julho de 2011 e resultou na formação de uma amostra com 248 pessoas.

O questionário era composto por oito questões fechadas que tratavam sobre características do respondente e opiniões e preferências relativas à compra de camisetas.

As quatro primeiras perguntas do questionário eram referentes a características do respondente, solicitando informações do gênero sexual, idade, escolaridade e renda familiar (opcional). As demais questões tratavam das preferências de compra.

A pergunta cinco solicitava para o respondente ordenar, de acordo com a sua preferência, 12 produtos diferentes, que combinavam os três tipos de marca estudados com três diferentes níveis de preço e de qualidade, fatores esses importantes na avaliação de alternativas de compra (KELLER, 2002; KOTLER; KELLER, 2006; PEREZ, 2004; AAKER, 1996; AAKER; JOACHIMSTHALER, 2007; KAPFERER, 2003, 2004a, 2004b). Os produtos foram apresentados aos respondentes em ordem aleatória, a fim de se evitar o viés decorrente da sequência de exposição dos objetos.

Uma camiseta branca de manga curta sem estampas, outra com o símbolo de uma famosa causa social estampado na frente e uma terceira com o logo de uma marca de roupas, que faz muitos comerciais na televisão, estampado na face frontal, foram as descrições que representavam, na ordem, as marcas genérica, social e de fabricante. 
Os níveis de preço e qualidade utilizados foram baixo, médio e alto, evitando-se medidas numéricas, pois, como a população de interesse era heterogênea em várias características, uma medida desse tipo poderia ter diferente interpretação para cada pessoa.

Na sexta questão foi avaliada a diferenciação de preço dos três tipos de marca, descritos como na pergunta cinco, porém, agora se definiu que a qualidade dos produtos era mediana. Nessa questão solicitou-se à pessoa a precificação dos três tipos de camiseta.

Por fim, as duas últimas questões foram elaboradas para levantar dados em relação ao perfil de preferência dos respondentes em relação a camisetas. A questão sete solicitava para o respondente apontar a sua preferência entre três tipos de camiseta, a mais barata, a que é anunciada na TV e a produzida por uma empresa envolvida em causas sociais e/ou ambientais. A questão oito apresentava quatro características das camisetas (qualidade, preço, marca e envolvimento com causa socioambiental), mostradas em ordem aleatória, e solicitava para a pessoa ordená-las pela sua importância na decisão de compra de uma camiseta.

Mediante um pré-teste com cinco pessoas, avaliou-se a adequação do conteúdo do instrumento de coleta e o tempo de preenchimento, o qual foi, em média, 11 minutos.

A análise dos resultados foi feita por meio de estatísticas descritivas e das técnicas análise conjunta e teste t para amostras relacionadas.

A análise conjunta (conjoint analysis) é uma técnica de análise multivariada da estrutura das preferências que permite entender o processo de decisão do consumidor no que diz respeito a produtos e marcas (HAIR et al., 2006). A medida de preferência calculada por essa técnica é a utilidade, a qual é o valor relacionado ao julgamento de preferência de um indivíduo que mede o nível de felicidade ou satisfação que ele obtém com uma escolha (HAIR et al., 2006; MANKIW, 2001).

A análise conjunta é uma técnica de dependência, tendo como variável dependente a preferência e como independentes as combinações de níveis de fatores (atributos). A análise conjunta faz lembrar da análise de experimentos. Entretanto, há diferenças entre essas abordagens. Nos experimentos o pesquisador, com base em uma grande quantidade de observações, controla diretamente uma ou mais variáveis independentes para determinar o efeito sobre a variável dependente e também inibe o efeito de possíveis variáveis exógenas de modo que estas não interfiram nos resultados. Por outro lado, a análise conjunta assume que qualquer grupo de objetos (no caso, camisetas) é avaliado como uma coleção de atributos, sendo aplicada em levantamentos de informações referentes a um único indivíduo ou a um grupo de indivíduos, visando detectar reações de consumidores e avaliar combinações pré-determinadas de atributos representantes de produtos ou serviços.

A execução da análise conjunta baseou-se nos dados gerados na questão cinco. Os produtos foram montados utilizando-se a opção orthogonal design do programa estatístico Statistical Package for Social Sciences (SPSS) 9.0, sendo que nove deles são estímulos planejados, utilizados para calcular as utilidades, e três deles são estímulos de validação (holdout), ou seja, são casos julgados pelos respondentes, mas não usados para estimar as utilidades, apenas servindo para confirmar a validade interna delas (Quadro 1).

A questão cinco atende às suposições teóricas da análise conjunta de que o comprador percebe um produto como um conjunto de atributos que intervêm num certo nível e diferenciam as ofertas, e de que o comprador faz sacrifícios em alguns atributos para beneficiar outros (LAMBIN, 2000). Ela também atende às seguintes exigências dessa técnica:

serem atributos determinantes da escolha e não só atributos importantes; 2) serem atributos independentes ou não redundantes, ou seja, não sistematicamente 
correlacionados, a presença de um não implica a presença de outro; 3) descreverem o produto o mais completamente possível, o que implica que o julgamento deve poder apoiar-se no conjunto dos atributos, ou pelo menos nos mais importantes; 4) serem atributos manipuláveis pela empresa que poderá agir sobre o nível de intervenção dos atributos (LAMBIN, 2000, p. 164).

Quadro 1: Estímulos utilizados na análise conjunta

\begin{tabular}{|c|c|c|c|c|}
\hline & Tipo de Marca & Preço & Qualidade & Tipo de Estímulo \\
\hline \multirow{12}{*}{ 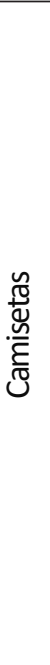 } & Fabricante & Baixo & Alta & Planejado \\
\hline & Fabricante & Alto & Média & Planejado \\
\hline & Genérica & Alto & Alta & Planejado \\
\hline & Genérica & Médio & Média & Planejado \\
\hline & Genérica & Baixo & Baixa & Planejado \\
\hline & Social & Médio & Alta & Planejado \\
\hline & Social & Alto & Baixa & Planejado \\
\hline & Fabricante & Médio & Baixa & Planejado \\
\hline & Social & Baixo & Média & Planejado \\
\hline & Fabricante & Alto & Alta & Validação \\
\hline & Social & Médio & Média & Validação \\
\hline & Genérica & Alto & Baixa & Validação \\
\hline
\end{tabular}

Descrição fornecida da camiseta segundo a marca associada: Genérica: Sem estampas; Social: Possui o símbolo de uma famosa causa social estampado na frente; Fabricante: Possui o símbolo de uma marca de roupas, que faz muitos comerciais na TV, estampado na frente.

Para processar a análise conjunta, usou-se uma sintaxe do software SPSS 9.0, no qual as classificações das doze camisetas são os dados de entrada, sendo designados como dados ordenados (rank). Quanto ao relacionamento dos níveis dos fatores, nenhuma suposição foi feita sobre a preferência pelos tipos de marca. Quanto à variável qualidade, assumiu-se que níveis maiores são os preferidos; o oposto ao adotado para o fator preço, sendo que níveis menores devem ser esperados como os preferidos.

Por fim, embora tenha requisitos conceituais, a análise conjunta possui baixas exigências estatísticas, sem a necessidade de realização de testes de normalidade, homocedasticidade, linearidade e independência das variáveis.

O teste t para amostras relacionadas é uma técnica paramétrica para avaliar a significância estatística da diferença entre as médias de duas amostras dependentes de uma variável, por exemplo, avaliações dos entrevistados sobre dois produtos (COOPER; SCHINDLER, 2003; HAIR et al., 2006).

Essa técnica é aplicada aos escores-diferença, os quais podem ser obtidos a partir dos dois valores de cada sujeito submetido às duas condições, e estabelece como hipótese nula o fato de que não há diferença entre as médias das duas situações analisadas (ANDERSON et al., 2008; COOPER; SCHINDLER, 2003; SIEGEL; CASTELLAN, 2006).

O teste $t$ assume que os escores-diferença são extraídos de uma distribuição normal, o que implica que as variáveis são medidas pelo menos em uma escala intervalar; porém, quando o número de observações analisadas é maior do que 30, aproxima-se a distribuição delas à normal, 
mesmo elas não possuindo essa característica (ANDERSON et al., 2008; COOPER; SCHINDLER, 2003; SIEGEL; CASTELLAN, 2006).

Neste estudo, o teste $t$ foi processado com os preços atribuídos a cada tipo de camiseta apresentado na questão seis, com o objetivo de medir estatisticamente se um tipo de marca consegue desfrutar de um preço diferencial em relação aos demais.

Como os preços dos três tipos de camiseta foram atribuídos por todos os respondentes, esses dados atendem à exigência da técnica de dependência, ou relacionamento, das amostras analisadas. E, visto que a quantidade de respostas avaliadas é maior do que 30, desconsidera-se a necessidade de distribuição normal delas e, desse modo, satisfaz-se outro requisito do teste t. Finalmente, para a realização desse teste, utilizou-se o programa estatístico SPSS 9.0 e o nível de erro foi fixado em $1,67 \%$, pois, como foram realizadas, de modo separado, três comparações de média para cada grupo avaliado, utilizou-se a abordagem da desigualdade de Bonferroni para ajustar o nível de erro, a qual, de acordo com Hair et al.(2006), consiste em dividir o valor de significância (alfa) proposto, que nesse estudo é $5 \%$, pelo número de testes estatísticos realizados, ou seja, três, resultando em um grau de significância mais exigente.

O quadro 2 relaciona as análises propostas neste trabalho com as ferramentas estatísticas e variáveis utilizadas para realizá-las.

Quadro 2: Relação das análises propostas com as técnicas estatísticas e as variáveis de estudo

\begin{tabular}{|c|c|c|}
\hline Análise Proposta & Técnica Estatística & Variáveis de Estudo \\
\hline $\begin{array}{l}\text { Importância da marca na escolha } \\
\text { de uma camiseta }\end{array}$ & \multirow{2}{*}{ Análise conjunta } & \multirow{2}{*}{$\begin{array}{l}\text { Ordenação das opiniões de preferência } \\
\text { das doze camisetas apresentadas }\end{array}$} \\
\hline $\begin{array}{l}\text { Predileção pelas camisetas de mar- } \\
\text { ca social, genérica e de fabricante }\end{array}$ & & \\
\hline $\begin{array}{l}\text { Relação dos três tipos de marca } \\
\text { com o preço atribuído à camiseta }\end{array}$ & $\begin{array}{l}\text { Teste t para amos- } \\
\text { tras relacionadas }\end{array}$ & $\begin{array}{l}\text { Valor citado para cada uma das três cami- } \\
\text { setas avaliadas; gênero sexual: preferência } \\
\text { declarada por um tipo de marca }\end{array}$ \\
\hline
\end{tabular}

\section{ANÁLISE DOS RESULTADOS}

A seguir são apresentados os resultados deste estudo, sendo que a primeira parte resume o perfil da amostra, em seguida exibe-se a análise da importância e da preferência dos atributos estudados de uma camiseta para amostra e, por último, expõe-se o estudo do diferencial de preço atribuído aos tipos de marcas pelos respondentes.

\section{Perfil da amostra}

A amostra utilizada neste estudo é composta de 248 pessoas. Há um equilíbrio entre os gêneros sexuais: 126 mulheres ( $51 \%$ da amostra) e 122 homens (49\% dos entrevistados), conferindo a ambos praticamente o mesmo peso nos resultados.

Quanto à distribuição etária, 80\% da amostra (198 pessoas) encontram-se entre 18 e 35 anos, sendo que 53\% possuem idade entre 18 e 26 anos (131 respondentes). As idades com maior representatividade são 19 e 26 anos (23 e 22 casos, respectivamente), ambas com aproximadamente $9 \%$ da amostra, e o valor máximo encontrado foi 65 anos.

Em relação ao grau de instrução, devido à população focalizada e ao procedimento 
amostral, 99\% da amostra está concentrada nos níveis pós-graduação, superior completo e superior incompleto (109, 46 e 90 pessoas, respectivamente).

Com relação à renda familiar mensal, há uma concentração de quase $70 \%$ da amostra (171 casos) em respondentes com renda familiar mensal maior ou igual a $\mathrm{R} \$ 5.000$ (maior, ainda, entre os homens: 76\%), a qual decorre do método de coleta de dados, visto que pessoas com maior instrução normalmente possuem maior renda familiar (FURRIER, 2008).

Quanto à preferência aos tipos de marcas, a camiseta mais barata (genérica) é a preferida (38\%), seguida pela social (33\%) e pela de marca de fabricante (29\%).

A camiseta mais barata, associada à marca genérica, compete no mercado pela melhor relação custo-benefício. $E$, entre o grupo de respondentes do sexo masculino, essa preferência é ainda maior, $43 \%$, versus o segundo tipo de marca mais escolhido pelos homens, a de fabricante, que possuía $33 \%$ das respostas desse grupo.

A camiseta cuja comercialização possui envolvimento, direto ou indireto, com uma causa social e/ou ambiental teve expressiva aceitação da amostra, 33\%, sendo esse número muito próximo da preferência de $37 \%$ citada por Produtos (2008). Constatou-se, também, que das 81 pessoas que escolheram a marca social, 51 eram mulheres. Analisando-se somente os respondentes do sexo feminino, a preferência pela camiseta social salta para $40 \%$, a qual é seguida pela marca genérica, que conta com $31 \%$ da preferência das mulheres. Esses dados demonstram que a marca social possui uma maior aceitação entre o público feminino, semelhante ao que foi encontrado em estudo da Letshal, o qual apontava, de acordo com Magalhães (2011), que 51\% das mulheres se preocupam mais em ajudar os outros.

Na ordenação, pela importância para a decisão de compra, de quatro atributos de camisetas, notou-se que a qualidade é, com vantagem, o primeiro fator em termos de importância (68\% da amostra), e preço é o segundo atributo mais importante (58\%). A marca e o envolvimento dela com uma causa socioambiental são os fatores menos importantes.

A leitura da preferência por tipos de marcas em conjunto com a ordenação dos atributos mostra que primeiramente uma marca precisa aplicar um preço considerado justo e transmitir a percepção de qualidade, a fim de ser considerada pelo consumidor, para somente então diferenciar-se dos concorrentes e ser escolhida por meio dos seus significados e envolvimento com causas sociais e/ou ambientais. E, há um grupo de respondentes que ainda é subdesenvolvido em termos de consumo dos significados da marca, preferindo produtos que tragam benefícios tangíveis, sobretudo, preço baixo.

\section{Análise da importância dos atributos na preferência de compra}

Nessa pesquisa os respondentes apenas forneceram informações sobre a preferência a doze estímulos (combinações de níveis de tipos de marca, preços e qualidade de camisetas). A premissa da análise conjunta é que a preferência por uma combinação de níveis (utilidade total) pode ser decomposta nas preferências específicas de cada nível (utilidades parciais). Esta técnica gerou, iterativamente, as importâncias dos níveis dos fatores (não declaradas pelos respondentes) de modo a maximizar a correlação entre o ranking de preferência (variável dependente) coletado e o ranking de preferência recomposto a partir das estimativas das utilidades parciais. $O$ teste estatístico aplicado nessa análise corresponde à medida de significância da correlação entre os dois rankings: as preferências declaradas e as estimadas.

A análise conjunta das opiniões de preferência de compra da amostra em relação às doze camisetas testadas forneceu um modelo ajustado aos dados, com correlação de postos de 
Kendall de 0,817 , mas com baixa validade interna, com correlação de Kendall para o conjunto de validação (holdout) de 0,333. Ademais, foram obtidos cinco casos com dois reversals - respostas contrárias ao relacionamento dos níveis assumidos para algum fator - e 42 com somente um reversal.

A fim de melhorar a qualidade do modelo de preferência gerado para a amostra, procedeu-se com a remoção de alguns casos, avaliando-se em cada retirada a possível melhora dos indicadores de qualidade do modelo antes da próxima exclusão. Para melhoria dos indicadores de qualidade do modelo, foram necessárias 64 exclusões, sendo 47 referentes aos casos que apresentavam reversals e os outros 17 não possuíam reversals, mas tinham o módulo da correlação de validação menor ou igual a 0,333 e da correlação da modelagem abaixo de 0,7. A ordem de exclusão desses 17 casos foi do menor módulo de correlação de Kendall do modelo ao mais próximo do valor 0,7. Dessas 64 exclusões, 31 eram mulheres e 33 eram homens, apenas 1 caso não possuía ensino superior completo ou incompleto ou pós-graduação, 41 pessoas apresentavam renda igual ou maior do que $\mathrm{R} \$ 5000$ e a média de idade era de 30 anos e $80 \%$ dos casos possuíam menos do que 40 anos.

O modelo de preferência de compra gerado após as exclusões apresentou melhor ajuste aos dados - correlação de postos de Kendall 0,833 - e validade interna, com correlação de Kendall de 0,816; desse modo, esse é o modelo final adotado.

Na opinião da amostra, a qualidade de uma camiseta é o atributo mais importante (importância média de $43,3 \%)$, seguida pelo tipo de marca $(32,7 \%)$ e o preço $(24 \%)$. Essa ordenação gerada pela análise conjunta é diferente da que havia sido constatada quando foi pedido para os respondentes ordenarem, segundo a importância em uma situação de compra de uma camiseta, esses três atributos mais o envolvimento com uma causa social e/ou ambiental, sendo que nesse caso, apesar de a qualidade ainda ter sido citada como o principal, o preço havia obtido uma maior importância em relação à marca. Logo, embora a amostra não declare, inconscientemente a marca tem maior importância em relação ao preço na preferência dela por diferentes camisetas.

A maior importância da marca, em comparação ao preço, na preferência da amostra, revela um bom nível de desenvolvimento dos respondentes em termos de conscientização do consumo de significados da marca e opõe-se à ideia de que as pessoas escolhem produtos pelo preço, sempre mais barato, independente da marca. Além disso, ao ser a qualidade o atributo mais importante, conclui-se que uma marca deve, primeiramente, apresentar benefícios tangíveis para, depois, diferenciar-se por meio dos seus significados. $O$ interessante é que a marca pode reforçar a percepção dessa qualidade e isso novamente enfatiza a importância da marca na amostra.

Em relação aos tipos de marca, obteve-se que a marca genérica é a preferida (utilidade de $0,2283)$. A marca social e de fabricante possuem, respectivamente, utilidade de -0,0417 e -0,1866; assim, a amostra apresenta certa aversão a esses tipos de marca, sendo que o último deles tem um impacto negativo na preferência quase tão forte quanto a influência positiva da marca genérica. Essa ordem de preferência pelos tipos de marca é coerente com a declaração feita pelos respondentes durante a coleta de dados, quando $38 \%$ deles disseram preferir a marca genérica, $33 \%$ a social e $29 \%$ a de fabricante.

A maior preferência pela marca genérica revela que os respondentes preocupam-se em não transmitir os seus valores e ideias, o que ocorreria com marca de fabricante ou social, que comunicaria os significados associados. E a maior escolha pelas marcas genéricas reduz a possibilidade de se criar fidelidade a elas, pois estas possuem pouca ou nenhuma diferenciação, sendo apenas associadas à boa relação qualidade-preço. 
Considerando-se os três níveis de qualidade, a estrutura de preferência apresentou uma maior utilidade ao nível alto, valor intermediário para nível médio e menor ao estado baixo, sendo esse o movimento pressuposto para o fator, visto que em uma relação comercial, supõe-se que uma pessoa prefira a maior quantidade possível de benefícios (entre eles a qualidade) para cada unidade de recursos dados em troca. Esse resultado converge com o estudo de Pennanen e Luomala (2004) apud Afsar (2014) que reforçam a tendência de preferência dos consumidores por produtos com nível alto de qualidade.

Quanto ao fator preço, ficou clara a preferência por camisetas com preços mais baixos, o que é coerente com a maior inclinação da amostra para as marcas genéricas e com o pressuposto para esse fator na execução da análise conjunta, que estabelecia que as pessoas preferem produtos com o menor preço a similares de preço maior.

Pelos ajustes lineares de cada fator em relação à preferência por camisetas, inerentes à análise conjunta, têm-se, pelos coeficientes (qualidade: 1,8351 versus preço: 1,0362), grande impacto da qualidade, sendo $77 \%$ maior do que o do fator preço.

Logo, para consideração dos respondentes, a marca, primeiro, precisa reforçar a percepção de qualidade do produto, para somente depois atuar como um elemento de diferenciação, restando ao preço o papel de critério de desempate no caso de não diferenciação entre marcas. Esse resultado é convergente com a afirmação de Steenkamp et al. (2003) de que as marcas devem se focar em criar e comunicar qualidade ao invés de benefícios em termos de status e prestígio. E, o tipo de camiseta preferido pela amostra é o de marca genérica, que não exibe nenhum signo aparente, com alta qualidade e baixo preço, sendo essas duas últimas características coerentes com o tipo de marca preferido, pois as marcas genéricas concorrem por meio do oferecimento de produtos com a melhor qualidade a um determinado preço.

\section{Diferencial de preço atribuído aos tipos de marca}

Uma forma importante de se medir a apreciação por uma marca é o preço adicional que os consumidores estariam dispostos a pagar para continuarem comprando-a (D'EMIDIO, 2009). Para essa análise, utilizaram-se as opiniões dos 248 respondentes abordados. Durante a coleta de dados, pediu-se para eles escreverem o valor que pagariam por uma camiseta branca de manga curta e qualidade média de cada tipo de marca estudado. Com base nesses dados, executou-se o teste t para amostras relacionadas a fim de se verificar, ao nível de erro de $1,67 \%$, se a média de preço de cada tipo de camiseta é estatisticamente diferente.

Tabela 1: Medidas de dispersão e posição dos preços das camisetas atribuídos pela amostra

\begin{tabular}{|c|c|c|c|c|c|}
\hline Tipo de Marca & Mínimo & Máximo & Mediana & Média & Desvio-Padrão \\
\hline Genérica & 1,00 & 100,00 & 20,00 & 23,67 & 11,79 \\
\hline Social & 0,00 & 90,00 & 26,50 & 29,53 & 14,95 \\
\hline Fabricante & 1,50 & 100,00 & 35,00 & 37,20 & 18,89 \\
\hline
\end{tabular}

Como exibido na tabela 1, as três marcas possuem valores máximos e mínimos muito próximos, sendo que o maior preço é visto na genérica e na de fabricante ( $R \$ 100,00$, ambas) e o menor é constatado na social ( $R \$ 0,00$, ou seja, só aceitaria a camiseta se fosse sem custo). 0 desvio-padrão é alto, representando aproximadamente $50 \%$ da média dos preços para cada tipo de marca. Tentou-se reduzir essa variabilidade por meio da exclusão de alguns possíveis outliers; contudo, como a redução na dispersão foi pouca, decidiu-se conservar todos os casos e assumir 
que essa alta variância nas respostas reflete a diversidade de opiniões dos participantes.

Em relação ao teste t para amostras relacionadas realizado com as médias de preços dos três tipos de marca (Tabela 2), rejeita-se, ao nível de erro de 1,67\%, a hipótese nula, ou seja, há indícios estatísticos de que as três médias são diferentes. Assim, é possível afirmar que, na opinião da amostra, camisetas com marca de fabricante, em média, são as mais valiosas, seguidas pela social e genérica, sugerindo-se que o investimento no desenvolvimento do patrimônio de uma marca possibilita que a de fabricante e a social consigam aplicar, em média, preços diferenciados em relação à genérica ( $57 \%$ e $25 \%$ a mais, respectivamente), sendo que, por trabalhar com muitas propagandas e associar-se ao mercado da moda e, às vezes, de luxo, a de fabricante consegue desfrutar de um diferencial maior do que a social.

Tabela 2: Teste t das médias dos preços das camisetas atribuídos pela amostra

\begin{tabular}{|c|c|c|}
\hline Marcas relacionadas & $\mathbf{T}$ & Sig. (bicaudal) \\
\hline Genérica/Social & $-8,498$ & 0,000 \\
\hline Genérica/Fabricante & $-13,044$ & 0,000 \\
\hline Social/Fabricante & $-8,523$ & 0,000 \\
\hline
\end{tabular}

Tabela 3: Medidas de dispersão e posição dos preços das camisetas atribuídos pela amostra segundo gênero sexual

\begin{tabular}{|c|c|c|c|c|c|c|}
\hline Gênero sexual & Tipo de Marca & Mínimo & Máximo & Mediana & Média & Desvio-Padrão \\
\hline \multirow{3}{*}{$\begin{array}{c}\text { Masculino } \\
(122 \text { casos) }\end{array}$} & Genérica & 1,00 & 100,00 & 20,00 & 23,01 & 12,55 \\
\cline { 2 - 7 } & Social & 7,50 & 90,00 & 25,00 & 28,62 & 14,65 \\
\cline { 2 - 7 } & Fabricante & 1,50 & 100,00 & 35,00 & 37,28 & 19,48 \\
\hline \multirow{3}{*}{$\begin{array}{c}\text { Feminino } \\
(126 \text { casos) }\end{array}$} & Genérica & 5,00 & 50,00 & 20,00 & 24,31 & 11,01 \\
\cline { 2 - 7 } & Social & 0,00 & 75,00 & 30,00 & 30,43 & 15,23 \\
\cline { 2 - 7 } & Fabricante & 7,00 & 90,00 & 35,00 & 37,13 & 18,37 \\
\hline
\end{tabular}

Avaliando as médias de preço dos tipos de marca por gênero sexual (Tabela 3), os homens atribuem os preços máximos mais altos para os três tipos de camiseta e, também, os mínimos mais baixos para a genérica e de fabricante, restando às mulheres o preço mais baixo para a social. Porém, em termos de média e mediana, as mulheres possuem valores maiores do que os homens para as marcas genérica e social, ou seja, embora não atribuam preços extremos, os valores citados por elas estão em média em um patamar mais alto do que os pensados pelos homens, sendo que isso é comprovado pelo desvio-padrão relativo à média, o qual é mais alto para os respondentes do sexo masculino (variando de $51 \%$ da média da marca social a $54 \%$ para a genérica) do que para os do feminino (variando de $45,3 \%$ da média da marca genérica a $50 \%$ no caso da social). É interessante notar que a maior diferença entre as médias e as medianas de preços entre homens e mulheres reside na marca social, sendo que o primeiro grupo atribui preço menor do que o último.

Conforme a tabela 4 , ao nível de erro de 1,67\%, rejeita-se a hipótese nula do teste t para amostras relacionadas das médias de preços dos três tipos de marca; logo, há indícios estatísticos de que elas são diferentes tanto para homens quanto para mulheres. Assim, pode-se afirmar que, para ambos os sexos, camisetas com marca de fabricante são, em média, as mais valiosas, seguidas pela social e genérica, sugerindo-se, analogamente à amostra total, que o investimento no desenvolvimento do patrimônio de uma marca permite que a de fabricante e a social apliquem, em média, preços diferenciados em relação à genérica (62\% e $24 \%$ a mais, respectivamente, para os homens e $53 \%$ e $25 \%$, nessa ordem, para as mulheres). 
Nota-se, ainda, que os homens atribuem, em média, preços menores do que as mulheres, mostrando maior exigência em relação ao fator preço das marcas, e consideram um diferencial de preço maior da marca de fabricante em relação à social quando comparados com as mulheres.

Tabela 4: Teste $t$ das médias dos preços das camisetas atribuídos pela amostra segundo gênero sexual

\begin{tabular}{|c|c|c|c|}
\hline Gênero sexual & Marcas relacionadas & $\mathbf{T}$ & Sig. (bicaudal) \\
\hline \multirow{2}{*}{$\begin{array}{c}\text { Homens } \\
(122 \text { casos) }\end{array}$} & Genérica/Social & $-5,502$ & 0,000 \\
\cline { 2 - 4 } & Genérica/Fabricante & $-8,750$ & 0,000 \\
\cline { 2 - 4 } & Social/Fabricante & $-6,206$ & 0,000 \\
\hline \multirow{2}{*}{$\begin{array}{c}\text { Mulheres } \\
(126 \text { casos) }\end{array}$} & Genérica/Social & $-6,254$ & 0,000 \\
\cline { 2 - 4 } & Genérica/Fabricante & $-9,873$ & 0,000 \\
\cline { 2 - 4 } & Social/Fabricante & $-5,865$ & 0,000 \\
\hline
\end{tabular}

$\mathrm{Na}$ análise das médias de preço dos tipos de marca por preferência, a tabela 5 mostra que quem prefere a marca genérica e de fabricante atribui os preços máximos mais altos para as camisetas com os respectivos tipos de marca; mas, isso não ocorre para a marca social, à qual é atribuído o preço máximo pelo grupo que prefere a marca genérica. Para os três aglomerados, a marca de fabricante exibe o maior preço mínimo em relação às outras duas.

Tabela 5: Medidas de dispersão e posição dos preços das camisetas atribuídos pela amostra segundo preferência declarada de tipo de marca

\begin{tabular}{|c|c|c|c|c|c|c|}
\hline Preferência & Tipo de Marca & Mínimo & Máximo & Mediana & Média & Desvio-Padrão \\
\hline \multirow{3}{*}{$\begin{array}{c}\text { Genérica } \\
\text { (94 casos) }\end{array}$} & Genérica & 1,00 & 100,00 & 20,00 & 23,68 & 12,60 \\
\cline { 2 - 7 } & Social & 10,00 & 90,00 & 25,00 & 27,95 & 13,05 \\
\cline { 2 - 7 } & Fabricante & 1,50 & 80,00 & 35,00 & 34,08 & 16,24 \\
\hline \multirow{3}{*}{$\begin{array}{c}\text { Fabricante } \\
\text { (73 casos) }\end{array}$} & Genérica & 5,00 & 55,00 & 20,00 & 22,82 & 11,37 \\
\cline { 2 - 7 } & Social & 0,00 & 80,00 & 25,00 & 27,06 & 15,39 \\
\cline { 2 - 7 } & Fabricante & 7,00 & 100,00 & 40,00 & 42,79 & 20,30 \\
\hline \multirow{3}{*}{$\begin{array}{c}\text { Social } \\
(81 \text { casos) }\end{array}$} & Genérica & 5,00 & 50,00 & 20,00 & 24,43 & 11,26 \\
\cline { 2 - 7 } & Social & 5,00 & 75,00 & 30,00 & 33,60 & 15,91 \\
\cline { 2 - 7 } & Fabricante & 7,00 & 100,00 & 30,00 & 35,80 & 19,55 \\
\hline
\end{tabular}

Em termos de média e mediana, a marca de fabricante e a genérica sempre possuem os maiores e menores valores, respectivamente, não importando o grupo de respondentes. Diferente do esperado, somente a marca social e de fabricante apresentam os maiores valores de média e mediana entre os respondentes que preferem os respectivos tipos de marca, faltando o mesmo ocorrer com a marca genérica. $E$, em relação ao desvio-padrão, constata-se que ele é alto (coeficiente de variação, o qual é o desvio-padrão em relação à média, entre $46 \%$ e $57 \%$, inclusive); contudo, assume-se que essa alta variância nas respostas reflete a diversidade de opiniões dos participantes.

De acordo com a Tabela 6, rejeita-se a hipótese nula do teste t para amostras relacionadas das médias de preços dos três tipos de marca, exceto na comparação entre a marca social e de fabricante para o grupo que prefere a social, pois, nesse caso, a significância do teste $(13,8 \%)$ foi maior do 
que o limiar de rejeição, definido como 1,67\%.

Assim, para os optantes pela marca genérica e de fabricante, há indícios estatísticos de que as médias de preços dos três tipos de marca são diferentes. Para eles, camisetas com marca de fabricante são, em média, as mais valiosas, seguidas pela social e genérica, sugerindo-se, novamente, que o investimento no desenvolvimento do patrimônio de uma marca possibilita que a de fabricante e a social consigam aplicar, em média, preços diferenciados em relação à genérica ( $44 \%$ e $18 \%$ a mais, respectivamente, para os optantes pela marca genérica e $88 \%$ e $19 \%$, na mesma ordem, para os que preferem a de fabricante).

Tabela 6: Teste $t$ das médias dos preços das camisetas atribuídos pela amostra segundo preferência declarada de tipo de marca

\begin{tabular}{|c|c|c|c|}
\hline Preferência & Marcas relacionadas & $\mathbf{T}$ & Sig. (bicaudal) \\
\hline \multirow{3}{*}{$\begin{array}{c}\text { Genérica } \\
\text { (94 casos) }\end{array}$} & Genérica/Social & $-4,054$ & 0,000 \\
\cline { 2 - 4 } & Genérica/Fabricante & $-7,024$ & 0,000 \\
\cline { 2 - 4 } & Social/Fabricante & $-4,731$ & 0,000 \\
\hline \multirow{3}{*}{$\begin{array}{c}\text { Fabricante } \\
\text { (73 casos) }\end{array}$} & Genérica/Social & $-3,143$ & 0,002 \\
\cline { 2 - 4 } & Genérica/Fabricante & $-10,132$ & 0,000 \\
\cline { 2 - 4 } & Social/Fabricante & $-9,775$ & 0,000 \\
\hline \multirow{3}{*}{$\begin{array}{c}\text { Social } \\
\text { (81 casos) }\end{array}$} & Genérica/Social & $-7,977$ & 0,000 \\
\cline { 2 - 4 } & Genérica/Fabricante & $-6,166$ & 0,000 \\
\cline { 2 - 4 } & Social/Fabricante & $-1,498$ & 0,138 \\
\hline
\end{tabular}

É interessante citar que para o grupo que prefere a marca de fabricante, a diferença da média de preços entre a camiseta que possui e a de marca social é maior, muito devido ao valor mais alto atribuído à de marca de fabricante e, em parte, ao menor apreço desse grupo pela camiseta de marca social, vistos o menor preço mínimo e a média de preços em relação aos demais conjuntos de respondentes, o que é coerente com a observação de Ellwood (2004) de que respondentes que preferem esse tipo de marca desejam se agradar sem ficar com a consciência culpada e, desse modo, associam a marca social a grupos com estilo de vida indesejáveis.

Já para os que preferem a marca social, há indícios estatísticos de que a média de preços da marca genérica é diferente das demais, mas o mesmo não ocorre entre a social e a de fabricante. Portanto, camisetas com marca de fabricante e social possuem estatisticamente igual diferencial de valor, em média, quando comparadas com as genéricas, sugerindo-se que o investimento no desenvolvimento do patrimônio de qualquer um desses dois tipos de marca pode agregar, estatisticamente, o mesmo diferencial de valor para um produto em relação a uma versão genérica. $O$ adicional da média de preço da marca de fabricante e da social é, nessa mesma ordem, $47 \%$ e $38 \%$ maior em relação à marca genérica, sendo que esse é o grupo em que a marca social apresenta a maior percepção de valor.

Portanto, o investimento no patrimônio de uma marca gera maiores ganhos para uma empresa por meio da possibilidade de se aplicar preço diferenciado em relação a uma versão genérica do produto, sendo que as marcas de fabricante são as que desfrutam de maior percepção de valor. 


\section{CONCLUSÕES}

A grande proliferação atual de marcas e o crescente desafio da sua gestão motivaram a realização deste trabalho cujo objetivo foi estudar a influência de tipos de marcas (sociais, marcas genéricas e marcas de fabricante), níveis de preço e de qualidade percebida, sobre a preferência de compra de um produto.

A amostra deste trabalho consistiu de 248 respondentes e caracterizou-se por uma divisão quase igual entre os gêneros sexuais, uma concentração etária entre 18 e 35 anos, alto grau de instrução e renda familiar mensal, preferência declarada pelas camisetas mais baratas e pela qualidade e preço como os atributos citados como os mais importantes na decisão de compra desse produto.

O tipo de camiseta preferido é o de marca genérica, que não exibe nenhum signo aparente, com alta qualidade e baixo preço, sendo a qualidade, seguida pela marca e depois pelo preço, os atributos mais importantes para a preferência por uma camiseta.

Os resultados obtidos por meio do modelo de preferência da amostra sugerem que a marca mantém considerável importância na decisão do consumidor; porém, este ainda preocupa-se em escolher camisetas cuja marca seja uma garantia de benefícios tangíveis, como a qualidade, e, se possível, não expresse de forma explícita os seus valores e ideais por meio de logos estampados, ou seja, ele não está preocupado com os significados de uma marca, o que o torna mais difícil de ser fidelizado.

Avaliou-se, também, a capacidade dos três tipos de marca em aplicar preço diferenciado para uma camiseta. Conforme a resposta dos 248 participantes, camisetas com marca de fabricante, em média, são as mais valiosas, seguidas pela social e genérica, sugerindo-se, desse modo, que o investimento no desenvolvimento do patrimônio de uma marca possibilita que a de fabricante e a social consigam aplicar, em média, preços diferenciados em relação à genérica ( $57 \%$ e $25 \%$ a mais, respectivamente), sendo que, por trabalhar com muitas propagandas e relacionar-se ao mercado da moda e, às vezes, de luxo, a de fabricante consegue desfrutar de um diferencial maior do que a social.

Esses resultados variam em magnitude quando se analisa a opinião dos respondentes segundo o gênero sexual ou a preferência declarada pelo tipo de marca, porém, o entendimento permanece o mesmo. É interessante notar que para as pessoas que declararam gostar da marca social, o preço diferenciado da marca de fabricante e social é estatisticamente o mesmo, ou seja, esse é o grupo que valoriza as marcas que possuem uma dimensão "espiritual" tanto quanto as que são reconhecidas pelas propagandas e relação com o mercado da moda.

Este estudo proporcionou uma análise comparativa exploratória sobre a influência das marcas sociais, genéricas e de fabricante sobre a opinião de preferência de compra de uma camiseta, acrescentando-se novos insumos para o campo de estudo de marcas e para a prática de sua gestão.

A técnica de análise conjunta empregada proporcionou a aferição da influência de atributos (marca, preço e qualidade) e de seus respectivos níveis (fabricante, genérica, social; baixo, médio, alto; baixa, média, alta) na decisão de escolha por tipos de camisetas.

Em termos estratégicos, os resultados obtidos possibilitam:

o conhecimento da estrutura de preferência de cada indivíduo;

a definição da combinação ótima de características do produto pesquisado;

a identificação de segmentos de consumidores com diferentes importâncias

declaradas a cada atributo e respectivo nível; 
a detecção de ações de marketing voltadas para o potencial de mercado inerente a cada combinação de características do produto focalizado neste estudo.

Embora este trabalho tenha sido conduzido com o alto rigor acadêmico possível, resultados aqui apresentados devem ser lidos com algumas ressalvas. Primeiramente, as observações apresentadas limitam-se no tempo e espaço, pois, considerou-se a opinião de uma amostra da população brasileira maior de 18 anos e nos níveis mais altos de escolaridade, a qual foi coletada somente uma vez em março e julho de 2011. Assim, não é possível extrapolar esses dados para períodos muito distantes da coleta de dados, pois não se pode garantir que a opinião dos respondentes é consistente durante o tempo e para universos de pessoas diferentes do pesquisado.

Por não ter sido extraída uma amostra com seleção aleatória dos participantes, os resultados obtidos não podem ser generalizados para todo o universo de pesquisa e, desse modo, guardam um caráter de informações exploratórias.

Também, para o alcance do objetivo proposto, na análise conjunta das opiniões sobre as camisetas, utilizaram-se como variáveis de estudo apenas a marca e dois aspectos que ela pode influenciar (a qualidade e o preço). Outras características que podem ser importantes na avaliação de camisetas (por exemplo: cor, material e corte) não foram consideradas e, caso fossem, talvez pudessem conduzir a resultados diferentes dos apresentados. Por fim, por ser um estudo exploratório e focado em camisetas, os resultados aqui apresentados limitam-se somente a esse objeto, não sendo recomendada a extrapolação dele para outros produtos.

\section{REFERÊNCIAS}

AAKER, D. A. Building strong brands. New York: The Free Press, 1996.

AAKER, D. A.; JOACHIMSTHALER, E. Como construir marcas líderes. Porto Alegre: Bookman, 2007.

AFSAR B. Effect of perceived price, brand image, perceived quality and trust on consumer's buying preferences. Journal of Economics and Business Research, v. 20, n. 1, p. 7-20, 2014.

ALTAF J. G.; TROCCOLI I. R.; MOREIRA M. B. Vocêé o que você veste? A associação da autoidentidade do gay masculino ao vestuário de luxo. Rev. Adm. UFSM, v. 6, n. 4, p. 760-782, 2013.

ANDERSON, D. R.; SWEENEY, D. J.; WILLIAMS, T. A. Estatística aplicada à administração e economia. 2. ed. São Paulo: Cengage Learning, 2008.

BLOMQVIST, K. H.; POSNER, S. Three strategies for integrating CSR with brand marketing. Market Leader. [S.I.], 2004. Disponível em: <wwww.warc.com/marketleader>. Acesso em: 1 mai. 2008.

BRONN, P. S.; VRIONI, A. B. Corporate social responsibility and cause-related marketing: an overview. International Journal of Advertising, v. 20, n. 2, p. 207-221, 2001.

CALDWELL, N.; COSHALL, J. Measuring brand associations for museums and galleries using repertory grid analysis. Management Decision, v. 40, n. 4, p. 383-392, 2002.

CARROLL, A. Brand communications in fashion categories using celebrity endorsement. Journal of Brand Management, v. 17, n. 2, p. 146-158, 2009.

COOPER, D. R.; SCHINDLER, P. S. Métodos de pesquisa em administração. 7. ed. Porto Alegre: Bookman, 2003. 
CRAVENS, D. W.; PIERCY, N. F. Marketing estratégico. 8. ed. São Paulo: McGraw-Hill, 2007.

D’ASTOUS, A.; SAINT-LOUIS, O. National versus store brand effects on consumer evaluation of a garment. Journal of Fashion Marketing and Management, v. 9, n. 3, p. 306-317, 2005.

D'EMIDIO, M. O valor de marca: uma abordagem de equações estruturais. 2009. 115 p. Tese (Doutorado em Administração) - Programa de Pós-Graduação em Administração, Faculdade de Economia, Administração e Contabilidade, Universidade de São Paulo, São Paulo, 2009.

ELLWOOD, I. O livro essencial das marcas: tudo o que você precisa saber, em mais de 100 técnicas para aumentar o valor das marcas. São Paulo: Clio Editora, 2004.

FURRIER, M. T. Patrimônio de marca. In: F. A. SERRALVO (Org.). Gestão de marcas no contexto brasileiro. São Paulo: Saraiva, 2008a.

Posicionamento e reposicionamento de marcas. In: F. A. SERRALVO (Org.).

Gestão de marcas no contexto brasileiro. São Paulo: Saraiva, 2008b.

GILLIGAN, C.; GOLDEN, L. Re-branding social good: social profit as a new conceptual framework. Academy of Marketing Studies Journal, v. 13, n. 2, p. 97-117, 2009.

GRANATO, L. A. C.; PEREIRA, P. F. P. Ainda existem consumidores fieis? Rev. Adm. UFSM, v. 4, n. 1, p. 9-18, 2011.

HAIR, J. F. JR.; BLACK W. C.; BABIN B. J.; ANDERSON R. E.; TATHAM R. L. Multivariate data analysis. 6th ed. Upper Saddle River: Prentice Hall, 2006.

HOEFFLER, S.; KELLER, K. L. Building brand equity through corporate societal marketing. Journal of Public Policy \& Marketing, v. 21, n. 1, p. 78-89, 2002.

KAPFERER, J. N. As marcas, capital da empresa: criar e desenvolver marcas fortes. 3. ed. Porto Alegre: Bookman, 2003.

Bookman, 2004a.

Marcas à prova de prática: aprendendo com os erros. 2. ed. Porto Alegre:

. O que vai mudar as marcas. Porto Alegre: Bookman, 2004b.

KELLER, K. L. Strategic Brand Management. Upper Saddle River: Prentice Hall, 2002.

KOTLER, P.; KELLER, K. L. Administração de marketing. 12. ed. São Paulo: Pearson Prentice Hall, 2006.

LAFFERTY, B. A.; GOLDSMITH, R.E.; HULT, G. T. M. The impact of the alliance on the partners: a look at cause-brand alliances. Psychology \& Marketing, v. 21, n. 7, p. 509-531, 2004.

LAMBIN, J. J. Marketing estratégico. Lisboa: McGraw-Hill, 2000.

LEITCH, S. R.; DAVENPORT, S. Corporate brands and social brands: co-branding GM-free and UK supermarkets. International Studies of Management and Organizations, v. 37, n. 4, p. 45-63, 2007.

MAGALHÃES, G. F. Mais de 60\% das pessoas preferem marcas que ajudam a ajudar os outros. [S.I.], 2011. Disponível em: <www.infomoney.com.br>. Acesso em: 15 jun. 2011. 
MANKIW, N. G. Introdução à economia: princípios de micro e macroeconomia. 2. ed. Rio de Janeiro: Campus, 2001.

MORT, G. S.; WEERAWARDENA, J.; WILLIAMSON, B. Branding in the non-profit context: the case of Surf Life Saving Australia. Australasian Marketing Journal, v. 15, n. 2, p. 108-119, 2007.

MOWEN, J. C.; MINOR, M. S. Comportamento do consumidor. 1. ed. São Paulo: Prentice Hall, 2003.

PEREZ, C. Signos da marca: expressividade e sensorialidade. São Paulo: Pioneira Thomson, 2004.

PHAU, I.; LENG, Y. S. Attitudes toward domestic and foreign luxury brand apparel. Journal of Fashion Marketing and Management, v. 12, n. 1, p. 68-89, 2008.

POLONSKY, M. J.; JEVONS, C. Understanding issue complexity when building a socially responsible brand. European Business Review, v. 18, n. 5, p. 340-349, 2006.

PRACEJUS, J. W.; OLSEN, G. D.; BROWN, N. R. On the prevalence and impact of vague quantifiers in the advertising of cause-related marketing (CRM). Journal of Advertising, v. 32, n. 6, p. 19-28, 2004.

SERRALVO, F. A.; FURRIER, M. T. Tipologías del posicionamento de marcas, un estudio conceptual en Brasil y en España. Revista Galega de Economia, v. 14, n. 1-2, p. 1-15, 2005.

SIEGEL, S.; CASTELLAN JR., N. J. Estatística não-paramétrica para ciências do comportamento. 2. ed. Porto Alegre: Artmed, 2006.

STEENKAMP, J. B. E. M.; BATRA, R.; ALDDEN, D. L. How perceived brand globalness creates brand value. Journal of International Business Studies. v. 34, n. 1, p. 53-65, 2003.

VELTER, A. N.; BATTISTELLA L. F.; GROHMANN M. Z.; CASTRO A. E.; COSTA V. F.; HERMANN R. E. Atitudes dos consumidores a partir da teoria das pistas e da consciência ambiental: contribuições ao estudo do Green marketing. Rev. Adm. UFSM, v. 2, n. 3, p. 399-416, 2009. 